\title{
Patterns and predictors of food texture introduction in French children aged 4-36 months
}

\author{
Lauriane Demonteil ${ }^{1,2}$, Eléa Ksiazek ${ }^{1}$, Agnès Marduel $^{2}$, Marion Dusoulier ${ }^{2}$, Hugo Weenen ${ }^{3}$, \\ Carole Tournier ${ }^{1}$ and Sophie Nicklaus ${ }^{1 *}$ \\ ${ }^{1}$ Centre des Sciences du Goût et de l'Alimentation, CNRS, AgroSup Dijon, INRA, University Bourgogne Franche-Comté, \\ F-21000 Dijon, France \\ ${ }^{2}$ Blédina SA, Research \& Innovation, F-69760 Limonest, France \\ ${ }^{3}$ Danone Nutricia Research, Sensory \& Behavior Science, 3584 CT Utrecht, The Netherlands \\ (Submitted 24 November 2017 - Final revision received 16 July 2018 - Accepted 1 August 2018 - First published online 11 September 2018)
}

\section{Abstract}

The aims of this study were to describe which and when food textures are offered to children between 4 and 36 months in France and to identify the associated factors. An online cross-sectional survey was designed, including questions about 188 food texture combinations representing three texture levels: purées (T1), soft small pieces (T2) and hard/large pieces and double textures (T3). Mothers indicated which combinations they already offered to their child. A food texture exposure score (TextExp) was calculated for all of the texture levels combined and for each texture level separately. Associations between TextExp and maternal and child characteristics and feeding practices were explored by multiple linear regressions, per age class. Answers from 2999 mothers living in France, mostly educated and primiparous, were analysed. Over the first year, children were mainly exposed to purées. Soft and small pieces were slowly introduced between 6 and 22 months, whereas hard/large pieces were mainly introduced from 13 months onwards. TextExp was positively associated with children's number of teeth and ability to eat alone with their finger or a fork. For almost all age classes, TextExp was higher in children introduced to complementary feeding earlier, lower for children who were offered only commercial baby foods and higher for those who were offered only home-made/non-specific foods during the second year. Our study shows that until 12 months of age the majority of French children were exposed to pieces to a small extent. It provides new insights to further understand the development of texture acceptance during a key period for the development of eating habits.

Key words: Food texture: Exposure: Complementary feeding: Feeding practices: Feeding skills

Eating behaviour develops early in life through eating experiences. This learning process has been studied mainly in terms of taste and flavour exposures ${ }^{(1,2)}$. However, the role of food texture has been little investigated, while it could also influence food acceptance and liking at an early age ${ }^{(3,4)}$.

Children are usually first exposed to puréed foods at 4-6 months, with the beginning of complementary feeding (CF). With age, they are progressively exposed to more textures, ultimately allowing the transition to foods from the family table. The establishment of this new dietary pattern is actually synchronistic with the development of children's feeding skills ${ }^{(5,6)}$. Children start learning these skills with the introduction of CF when they begin to process semi-solid foods. With this type of texture, children learn to move food in the oral cavity for swallowing ${ }^{(1)}$. Later, they will learn to chew on food pieces ${ }^{(6)}$. Thus, the development of feeding skills during this period is important as it could ultimately determine to what extent a food with a given texture is accepted.

Literature suggests that the development of both feeding skills and food texture acceptance depends on texture exposure. A recent intervention study showed that changing the texture of commercial baby foods offered to 8-month-old children during 1 month can have an impact on the development of their chewing skills ${ }^{(7)}$. The improvement of chewing skills through exposure can also lead to an enhanced acceptance of food with harder textures. Indeed, several studies have shown that children's previous experience with textured foods was a predictor of later food acceptance. Acceptance of chopped carrots at 12 months was associated with familiarity with chopped textures $^{(8)}$. Data from the Avon Longitudinal Study of Parents and Children (ALSPAC) cohort showed that children who received lumpy foods before the age of 6 months had less feeding difficulties at 18 months and were less fussy than those

Abbreviations: BLW, baby-led weaning; CF, complementary feeding; TextExp, food texture exposure score.

* Corresponding author: S. Nicklaus, fax +33 380693227, email sophie.nicklaus@inra.fr 
who received such foods after 10 months (32 v. 52\%) ${ }^{(9)}$; moreover, such children had less eating difficulties and ate more fruits and vegetables at 7 years ${ }^{(10)}$. These data suggest the existence of a 'sensitive period' for the development of chewing skills and texture acceptance ${ }^{(11)}$ and then the necessity to advise a timely introduction of solid foods with a variety of textures during the CF period. However, this is addressed to a small extent, if at all, in current recommendations. As reviewed in 2015, most of the current guidelines focus mainly on the age of introduction to complementary foods and on the food groups to be introduced ${ }^{(6)}$. The $\mathrm{WHO}^{(12)}$ recommends introduction of $\mathrm{CF}$ at 6 months of age, while continuing to breast-feed, whereas other experts, for example, from European Food Safety Agency and European Society for Paediatric Gastroenterology, Hepatology and Nutrition (ESPGHAN), advise to begin CF between 4 and 6 months ${ }^{(13,14)}$. Once infants are introduced to $\mathrm{CF}$, the WHO recommends gradual change of consistency of complementary foods from semi-solid to solid foods and to increase the variety of foods offered ${ }^{(12)}$; recently, ESPGHAN provided specific guidelines outlining the types of textures appropriate for children for their age in months: they recommended discouraging prolonged use of puréed foods, and introducing lumpy foods by $8-10$ months at the latest ${ }^{(14)}$. In France, the National Program for Nutrition and Health (PNNS) guidelines advises introducing complementary foods at 6 months of age but never before 4 months, and to accustom infants to different textures, one texture at a time and in agreement with the development of children's feeding skills ${ }^{(15)}$. Otherwise, the French recommendations regarding feeding children between 0 and 3 years, which have not been updated since 2005, do not focus much on food texture.

Some information is available about differences between countries regarding how complementary foods are introduced and how parents manage a child's exposure to food variety ${ }^{(2,6,16,17)}$. In the ALSPAC cohort, $70 \%$ of British infants received food pieces for the first time between 6 and 9 months ${ }^{(9)}$. Recently, an alternative practice to spoon-feeding known as baby-led weaning (BLW) has grown in popularity in UK and New Zealand ${ }^{(18-20)}$. This practice consists of letting infants feed themselves finger food instead of being spoon-fed at the start of the CF period. In contrast, in France, a survey conducted in 2013 suggested that puréed foods are predominantly present in children's diets throughout the first year ( $47 \%$ at $8-11$ months) ${ }^{(21)}$. This suggests that introduction of food pieces may be limited during the first year, whereas it has been suggested that this is a window of opportunity to get children to accept texture ${ }^{(11)}$

Feeding practices are known to depend on various factors such as the parent's socio-economic background and children's characteristics. In literature, studied practices were mainly breastfeeding, the timing of CF introduction, the type of food groups introduced and the use of ingredients such as fat or sugar ${ }^{(22-25)}$. However, to date, little information is available on factors associated with parental choices regarding the texture of the foods they offer to their child. A British survey on weaning practices revealed that the choice of BLW $v$. spoon-feeding weaning methods is associated with maternal education, occupation and breast-feeding $^{(26)}$. More specifically, BLW was associated with later introduction of $\mathrm{CF}$, greater participation to family meals and exposure to family foods. Regarding texture introduction, a pilot study conducted in France on 181 parents showed that they were not systematically provided with recommendations for the introduction of new textures and that the introduction of new textures was the most $(16 \%)$ reported difficulty in $\mathrm{CF}^{(27)}$. Moreover, the timing of introducing pieces in children's diet was found to be associated with parental fear of choking ${ }^{(27,28)}$.

Thus, the introduction of textured foods is currently poorly detailed; information on how patterns of food texture consumption evolve with age is not available; and the factors associated with texture feeding practices are not known. Specifically, whether variables describing developmental readiness for food piece introduction are associated with their introduction was not studied, although parents are recommended to take this into account for piece introduction ${ }^{(14)}$.

In this context, the aim of this study is to describe which and when foods with different textures are offered to French children between 4 and 36 months of age and to determine the factors that are associated with the introduction of these food texture combinations in their diets.

\section{Methods}

Survey design

The data in this study were collected using a cross-sectional survey, which was launched online through a large convenience potential consumer database (approximately $n$ 700000 , declared to the national data protection authority Commission Nationale Informatique et Liberté (CNIL), no. 1824320v0), from September to December 2015. This is a database of the members of the web information programmes of Bledina brand, one of the main baby food manufacturers on the French market. A message was sent to all members in the database, inviting them to answer a survey conducted by the French National Institute for Agricultural Research (INRA) with a hyperlink connected to the survey, which was created with Sphinx ${ }^{\odot}$. The survey was aimed at members who had children between 4 and 36 months of age. It was approved by the local ethics committee (Comité de Protection des Personnes Est III, no. 2015-A00323-46). The survey design was inspired by a survey conducted in Japan that aimed to develop a reference standard to document progress in the transition to solid foods during the $\mathrm{CF}$ period ${ }^{(17,29)}$

The survey was composed of two parts. First, the participants were asked to report information on socio-demographic factors, their child's characteristics (age, sex, birth order, anthropometric information, number of visible teeth), the child's milk feeding mode (breast $v$. bottle) and feeding skills, maternal information sources on $\mathrm{CF}$, feeding history (attendance to daycare meal or meal taken with the family; eating with autonomy during meal), specific types of food preparation used (exclusive use of ready-prepared baby foods; use of both readyprepared baby foods and home-made foods; use of home-made foods or non-specific foods) and knowledge and application of BLW. The participants were also asked whether their child encountered difficulties during CF (e.g. allergy, pickiness) and 
their feelings with regard to the introduction of food pieces (e.g. unconcerned, eager or reluctant to introduce pieces), which they could comment on in an open comments field. In the second part, the parents were asked to indicate first whether they had offered each food or not, and second, for foods that had already been offered, which food texture combinations they had offered to their child at the time of the survey. The food list comprised sixty-one food items based on the literature and on previously identified French feeding practices ${ }^{(6,28,30)}$. These foods were classified into seven categories (1, commercial baby food products; 2 , vegetables; 3 , fruit; 4, meat-fish-eggs; 5 , cereal-based foods; 6 , cheese and dairy products; and 7, miscellaneous savoury and sweet foods). For each specific food item, different texture levels with increasing complexity (e.g. puréed, cooked, raw, etc.) were listed, which produced a total of 188 food texture combinations, as reported in online Supplementary Table S1. To help parents answer the questions, they were provided with photos illustrating the size of the pieces with a scale. Pieces were defined as 'large' if their size was $\geq 2 \mathrm{~cm}$.

\section{Study population}

Data from 3771 respondents were collected. The sample selection is described in Fig. 1. Some data were excluded from the analysis: from respondents other than mothers (fathers and grandmothers, $n$ 71), to focus the analysis on the main respondent category, and from twins ( $n$ 37), because it was not specified for which twin the answers were given. Of the remaining answers, data from children under 4 months of age and above 36 months of age, with a gestational age of under 37 weeks of amenorrhoea, with severe gastro-oesophageal reflux and/or tube-fed at birth were not included in the analyses. Responses with missing data with regard to food texture introduction were also excluded, leaving a sample size of 2999.

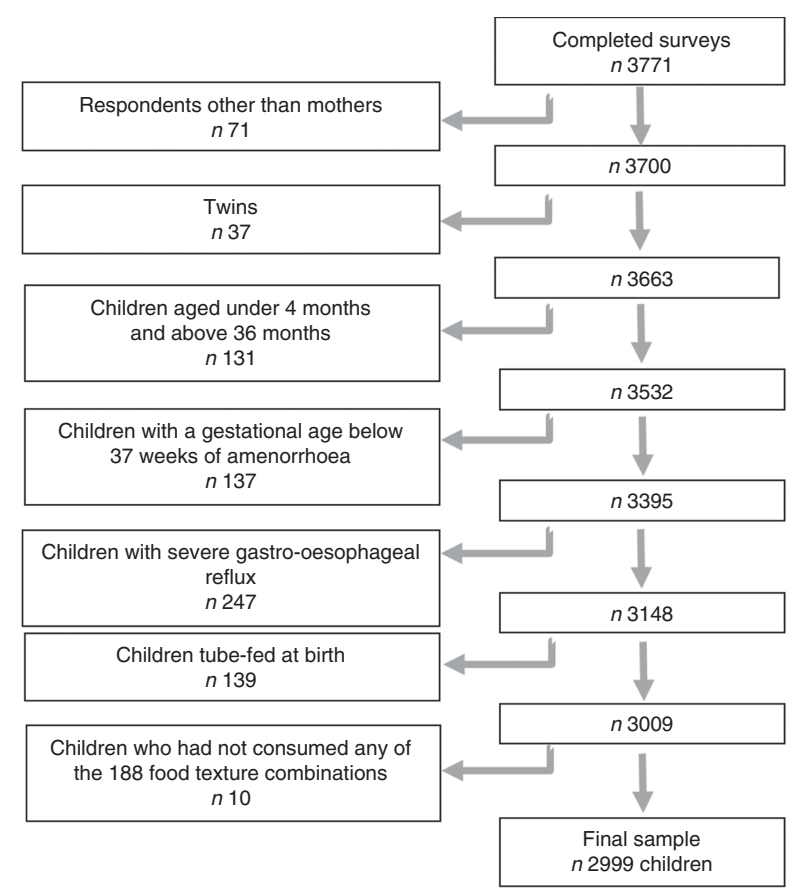

Fig. 1. Selection of the studied population.

\section{Texture exposure scores}

For each child, a food texture exposure score (TextExp) was calculated as the total number of all of the food texture combinations offered to him/her (range, 0-188).

To illustrate how exposure varies as function of the type of texture, we further classified the food texture combinations into three texture levels. These levels were defined according to the feeding skills required to process the food and according to the literature ${ }^{(6,28,30)}$. Simple textures (T1), which include smooth and rough purées, can be processed by sucking or limited tongue palate compression; intermediate textures (T2) that correspond to soft solid textures (small cooked pieces; soft foods, e.g. croissants) can be crushed thanks to the tongue palate compression or onto the gum; and large cooked and/or hard pieces (T3) required tongue, presence of teeth and masticatory movements to be swallowed. Double textures (pieces in a thin liquid phase) were also classified as T3 as their oral management is challenging too as it required swallowing the liquid phase while maintaining the pieces in the oral cavity for further breakdown (online Supplementary Table S1). On the basis of this classification, a texture exposure score was defined for each texture level (T1, T2 and T3) independently. It corresponds to the number of foods of this specific texture level offered to children. The sum of these three scores is equal to global TextExp.

\section{Data analysis}

Pattern of texture exposure. Given the cross-sectional nature of this sample and the dynamic evolution of children's diets from 4 to 36 months, the responses were split into fourteen age classes. The split was organised monthly during the first 12 months, considering the major changes in the infant's oral development during this period. Above 12 months, the responses were split into larger age classes: 13-15; 16-18; 19-21; 22-24; 25-29; and 30-36 months.

TextExp were presented as means and standard deviations, globally and per texture level and are studied graphically. To compare the scores (globally and per texture level) between the ages, one-way ANOVA was conducted. When significant differences were observed $(P$ value $<0.05)$, the means were compared using the Student-Newman-Keuls test.

Factors associated with texture exposure. The association between global TextExp and factors that included the children's and maternal characteristics, as well as feeding practices, was studied by age class. Children's characteristics such as sex, birth order, number of teeth, birth weight-for-length $z$-score, frequency of gagging, sitting up alone, eating with fingers and self-feeding with a spoon were analysed. The maternal characteristics were age, higher education level and type of information sources on CF that they had consulted, if any. The studied feeding practices were the infant's milk feeding mode, age of $\mathrm{CF}$, feeding history (meals taken with the family or at daycare), information on specific types of foods used (commercial baby foods, home-made foods and non-specific foods, the latter defined as commercial foods not specifically targeted for children of 
0-36 months, in other words, the commercial processed foods that the rest of the family eats), knowledge and application of BLW and feelings regarding texture introduction during $\mathrm{CF}$ (eager, reluctant, unconcerned). Linear regression models were used to study the variables that were associated with TextExp by age class. Bivariate analyses were first performed to study the relationships between the variables and TextExp. Their results are presented in online Supplementary Tables S2a and S2b but not further commented. All variables significantly associated with TextExp in bivariate analyses for more than two age classes were included in a common multivariate model, adjusted for education level. Significance was set at $P<0 \cdot 05$. Data were analysed using SAS 9.4 (SAS Institute Inc.).

\section{Results}

\section{Characteristics of the study population}

The participant characteristics are presented in Table 1 . The mean age of the mothers was 31.1 (sD 4.7) years. Most of them were born in France (94.6\%) and had attained an educational level of at least 2 or 3 years at a university, resulting in a degree (37.0\%). The most important sources of information with regard to $\mathrm{CF}$ were health professionals $(86.7 \%)$, specialised websites $(52 \cdot 9 \%)$ and family and friends (51.3\%).

The sample was composed mainly of first-born children $(77 \cdot 1 \%)$ and was balanced in terms of sex ( $51.9 \%$ of boys). The number of teeth increased gradually from 0.5 (SD 1.9) at 4-5 months to $18 \cdot 2$ (SD 2.4) at 30-36 months. The proportion of children who had a frequent gag reflex was $27.5 \%$ at 4-5 months and decreased with age to $14.0 \%$ at 30-36 months. The proportion of children who were able to sit alone often increased from $29.8 \%$ at $4-5$ months to $93.6 \%$ at 9 months and beyond; eating with fingers increased from $7 \cdot 2 \%$ at $4-5$ months to $90.6 \%$ at $19-21$ months; and concerning self-feeding with a fork, the proportion of children able to perform this skill only started to increase from 13-15 months (12.9\%) onwards, to $96 \cdot 1 \%$ of children at $25-29$ months and beyond.

With regard to feeding practices, of the included children, $62.9 \%$ had been or were breast-fed; the mean age of CF introduction was 4.9 (SD 1.1) months. The proportion of children who ate with the family between $4-5$ and 11 months was lower than $30 \%$, and increased steadily from 12 months until 30-36 months to reach $88 \%$. BLW was known by $9.7 \%$ of the mothers and was little practiced (1.8\% of the mothers). Most of the mothers ( $53 \%)$ used both commercial baby foods and home-made foods, whereas $33.8 \%$ used both home-made foods and non-specific foods (i.e. the same food as the other members of the family), and $13.2 \%$ used exclusively commercial baby foods. When asked about their feelings during the introduction of food pieces, $40.9 \%$ reported that they were unconcerned, $32.7 \%$ were reluctant and $26 \cdot 4 \%$ were eager to do it.

\section{Types of offered foods and textures}

The ten foods that were most offered to children were from the vegetable, potato, fruit and meat categories (online Supplementary Table S3): carrot, apple, green beans, zucchini/ eggplant/pepper/pumpkin, banana, potato, pear, spinach/leek, apricot and any type of meat. In addition, foods offered with a frequency higher than $50 \%$ were from the following food categories: commercial baby foods (vegetable or fruit jars, dairy products, cereals or biscuits), vegetables (cauliflower/broccoli, tomato, lentil), fruit (red berries, melon/watermelon), animal products (ham, any type of fish, eggs), cereal-based foods (rice, pasta, bread), dairy products (yogurt, petit-suisse cheese, spread cheese, custard) and biscuit categories. The non-specific foods, such as soft and hard cheese, chocolate, shrimp and cereals for breakfast (e.g. muesli), were offered with a frequency of $<50 \%$ (online Supplementary Table S3). The foods given to $<10 \%$ of the children were fruit salad, cucumber, mushroom, radish, salad and asparagus.

The texture levels of the most often offered foods (offered to at least $50 \%$ of the children) are presented in Table 2. Considering all of the food categories, the T1 texture level (puréed foods) was the only texture that was offered to infants at 4-5, 6 and 7 months $(5,10$ and 14 out of the thirty-eight T1 foods, respectively) (Table 2), mostly from the commercial baby foods, vegetable and fruit categories. From 8 to 9 months, almost half of all of the puréed vegetables and fruits were offered to children, and then the number increased steadily until 12 months $(35 / 38)$ and remained constant up to 30-36 months.

The T2 (cooked and soft pieces) and T3 (large cooked and/or hard pieces and double textures) texture levels were introduced, respectively, at 8 and 10 months, and they concerned meat, fish, cereal-based products (e.g. pasta, rice), commercial baby foods and miscellaneous savoury and sweet foods. At these ages, the proportions of offered $\mathrm{T} 2$ and $\mathrm{T} 3$ textures were rather low compared with the total number of food texture combinations surveyed (T2: 3/41 and T3: 2/109). At 12 months, at least $50 \%$ of the children received more than twice as many $\mathrm{T} 1$ textures than $\mathrm{T} 2$ and $\mathrm{T} 3$ textures combined. After 12 months, the exposure to $\mathrm{T} 2$ and $\mathrm{T} 3$ texture levels increased, and foods that were offered were from all of the food categories. At 13-15 months, 20/41 T2 foods and 14/109 T3 foods were given to children, and at 19-21 months 29/41 T2 foods and 40/109 T3 foods were offered. At 30-36 months, a maximum offer of 36/41 for T2 foods and 90/109 for T3 foods was observed.

\section{Pattern of food texture exposure scores distribution}

The distribution of texture exposure scores over age classes is shown in Fig. 2(a) and (b). The global TextExp scores for all textures combined increased steadily with age $\left(F_{13,2985}=763\right.$, $P<0.0001$ ) from 9.7 (SD 11.3) at 4-5 months to 134.4 (SD 27.2) at $30-36$ months. For the T1 level $\left(F_{13,2985}=294, P<0 \cdot 0001\right)$, the mean TextExp score increased steadily from 8.0 (SD 4.7 ) at 4-5 months to 27.2 (SD 5.9) at 12 months, and remained constant between 13-15 and 30-36 months. For the T2 level $\left(F_{13,2985}=797, P<0 \cdot 0001\right)$, the mean TextExp score increased from 6 to 22-24 months and then remained constant (from $0 \cdot 7$ (sD $3 \cdot 2)$ to $30 \cdot 4(\mathrm{sD} 5 \cdot 1))$. For the T3 level $\left(F_{13,2985}=656, P<0 \cdot 0001\right)$, the evolution pattern of the TextExp score is characterised by only a slight increase from 6 to 12 months (from $0 \cdot 6$ (SD 2.5) to $15 \cdot 3$ (SD 14.3)) and then a steeper increase from $13-15$ to 30 36 months (from 25.0 (sD 17.3) to 74.9 (sD 18.4)). 
Table 1. Characteristics of the participants in the study, globally and as per age class (Numbers and percentages; mean values and standard deviations)

\begin{tabular}{|c|c|c|c|c|c|c|c|c|c|c|c|c|c|c|c|c|}
\hline & \multicolumn{16}{|c|}{ Age class in months } \\
\hline & \multicolumn{2}{|c|}{$\begin{array}{c}\text { All } \\
(N 2999)\end{array}$} & \multirow{2}{*}{$\begin{array}{c}\begin{array}{c}4-5 \\
(N 142)\end{array} \\
\%\end{array}$} & \multirow{2}{*}{$\begin{array}{c}\begin{array}{c}6 \\
(N 283)\end{array} \\
\%\end{array}$} & \multirow{2}{*}{$\begin{array}{c}\begin{array}{c}7 \\
(N 235)\end{array} \\
\%\end{array}$} & \multirow{2}{*}{$\begin{array}{c}\begin{array}{c}8 \\
(N 243)\end{array} \\
\%\end{array}$} & \multirow{2}{*}{$\begin{array}{c}\begin{array}{c}9 \\
(N 187)\end{array} \\
\%\end{array}$} & \multirow{2}{*}{$\begin{array}{c}\begin{array}{c}10 \\
(N 195)\end{array} \\
\%\end{array}$} & \multirow{2}{*}{$\begin{array}{c}\begin{array}{c}11 \\
(N 168)\end{array} \\
\%\end{array}$} & \multirow{2}{*}{$\begin{array}{c}\begin{array}{c}12 \\
(N 137)\end{array} \\
\%\end{array}$} & \multirow{2}{*}{$\begin{array}{c}\begin{array}{c}13-15 \\
(N 370)\end{array} \\
\%\end{array}$} & \multirow{2}{*}{$\begin{array}{c}\begin{array}{c}16-18 \\
(N 279)\end{array} \\
\%\end{array}$} & \multirow{2}{*}{$\begin{array}{c}\begin{array}{c}19-21 \\
(N 254)\end{array} \\
\%\end{array}$} & \multirow{2}{*}{$\begin{array}{c}22-24 \\
(N 178) \\
\%\end{array}$} & \multirow{2}{*}{$\begin{array}{c}25-29 \\
(N 203) \\
\%\end{array}$} & \multirow{2}{*}{$\begin{array}{c}\begin{array}{c}30-36 \\
(N 125)\end{array} \\
\%\end{array}$} \\
\hline & $n$ & $\%$ & & & & & & & & & & & & & & \\
\hline \multicolumn{17}{|l|}{ Parental characteristics } \\
\hline Mother's age & & & & & & & & & & & & & & & & \\
\hline Mean & $31 \cdot$ & & 29.4 & $29 \cdot 6$ & $31 \cdot 1$ & 30.9 & $30 \cdot 6$ & $30 \cdot 6$ & $30 \cdot 6$ & 31.0 & 31.5 & $31 \cdot 2$ & $32 \cdot 1$ & $32 \cdot 0$ & $32 \cdot 4$ & $32 \cdot 6$ \\
\hline $\begin{array}{l}\text { SD } \\
\text { Partner's age }\end{array}$ & 4.7 & & $4 \cdot 6$ & 4.5 & $4 \cdot 8$ & 4.7 & $4 \cdot 4$ & 4.5 & $4 \cdot 2$ & 4.9 & 4.6 & 4.7 & 4.9 & $4 \cdot 2$ & $4 \cdot 6$ & 4.4 \\
\hline Mean & 33.4 & & 31.6 & 31.4 & $33 \cdot 2$ & $32 \cdot 8$ & $32 \cdot 8$ & $33 \cdot 0$ & 33.4 & 32.9 & 33.9 & 33.4 & 34.7 & 34.5 & 34.7 & 35.1 \\
\hline $\begin{array}{l}\text { SD } \\
\text { Mother's country of birth }\end{array}$ & $5 \cdot 7$ & & 5.9 & 5.4 & $5 \cdot 8$ & $5 \cdot 8$ & $4 \cdot 7$ & $5 \cdot 5$ & $6 \cdot 2$ & $5 \cdot 2$ & $5 \cdot 6$ & $5 \cdot 7$ & $5 \cdot 7$ & 5.4 & $5 \cdot 1$ & $6 \cdot 1$ \\
\hline $\begin{array}{l}\text { France, overseas departments and } \\
\text { territories included } \\
\text { Mother's education level }\end{array}$ & 2816 & $94 \cdot 6$ & $92 \cdot 2$ & $96 \cdot 4$ & $91 \cdot 8$ & $92 \cdot 1$ & $95 \cdot 7$ & $94 \cdot 3$ & $94 \cdot 1$ & 92.5 & $95 \cdot 4$ & $97 \cdot 2$ & 94.5 & $95 \cdot 5$ & $95 \cdot 1$ & $95 \cdot 2$ \\
\hline $\begin{array}{l}\text { High school diploma at the most } \\
2 \text { or } 3 \text { years university degree }\end{array}$ & $\begin{array}{l}1049 \\
1108\end{array}$ & $\begin{array}{l}35 \cdot 0 \\
37 \cdot 0\end{array}$ & $\begin{array}{l}43 \cdot 7 \\
36 \cdot 6\end{array}$ & $\begin{array}{l}40 \cdot 3 \\
34 \cdot 6\end{array}$ & $\begin{array}{l}40 \cdot 0 \\
35 \cdot 7\end{array}$ & $\begin{array}{l}36 \cdot 4 \\
32 \cdot 2\end{array}$ & $\begin{array}{l}39 \cdot 0 \\
38 \cdot 0\end{array}$ & $\begin{array}{l}32 \cdot 8 \\
35.9\end{array}$ & $\begin{array}{l}33.9 \\
37.5\end{array}$ & $\begin{array}{l}30 \cdot 6 \\
38 \cdot 7\end{array}$ & $\begin{array}{l}32 \cdot 4 \\
40 \cdot 3\end{array}$ & $\begin{array}{l}30 \cdot 8 \\
39 \cdot 5\end{array}$ & $\begin{array}{l}33 \cdot 5 \\
37 \cdot 0\end{array}$ & $\begin{array}{l}30 \cdot 3 \\
38 \cdot 2\end{array}$ & $\begin{array}{l}33.5 \\
36.5\end{array}$ & $\begin{array}{l}33 \cdot 6 \\
35 \cdot 2\end{array}$ \\
\hline Master and doctoral degree & 841 & 28.0 & 19.7 & $25 \cdot 1$ & $24 \cdot 3$ & 31.4 & 23.0 & 31.3 & 28.6 & 30.7 & 27.3 & 29.7 & 29.5 & 31.5 & 30.0 & 31.2 \\
\hline $\begin{array}{l}\text { Sources of information used by parents } \\
\text { for advice on CF practices }\end{array}$ & & & & & & & & & & & & & & & & \\
\hline Healthcare personnel $\dagger$ & 2371 & $86 \cdot 7$ & $85 \cdot 0$ & 91.5 & $86 \cdot 8$ & $82 \cdot 6$ & $90 \cdot 2$ & $85 \cdot 3$ & $83 \cdot 1$ & 88.8 & $87 \cdot 2$ & 88.1 & 86.5 & 84.0 & 88.2 & 82.6 \\
\hline Close relations $\dagger$ & 1403 & $51 \cdot 3$ & 55.6 & 55.4 & $50 \cdot 2$ & 51.8 & $49 \cdot 1$ & 51.4 & 51.4 & $40 \cdot 0$ & 52.4 & $52 \cdot 3$ & 51.5 & $50 \cdot 7$ & $50 \cdot 6$ & 49.6 \\
\hline Personal experience $\dagger$ & 713 & $26 \cdot 1$ & $26 \cdot 3$ & 17.5 & 24.6 & 25.9 & $27 \cdot 2$ & 24.6 & 27.0 & $32 \cdot 0$ & $24 \cdot 1$ & 30.4 & $32 \cdot 3$ & $26 \cdot 7$ & 22.5 & 30.4 \\
\hline Literature $\dagger$ & 1162 & 42.5 & 38.4 & 38.3 & 45.2 & 48.2 & 40.5 & $38 \cdot 3$ & 41.2 & 36.0 & 44.2 & $40 \cdot 8$ & 41.9 & $48 \cdot 0$ & 48.9 & 42.6 \\
\hline Webt & 1446 & $52 \cdot 9$ & 48.4 & 52.4 & 53.4 & 55.8 & $56 \cdot 7$ & 49.7 & 58.1 & 55.2 & 55.2 & 54.2 & 48.9 & $52 \cdot 0$ & 49.4 & $47 \cdot 8$ \\
\hline Children's characteristics & & & & & & & & & & & & & & & & \\
\hline Birth weight-for-length $z$-score & & & & & & & & & & & & & & & & \\
\hline Mean & -0 & & 0.04 & 0.04 & -0.05 & -0.10 & -0.01 & 0.16 & -0.09 & -0.12 & -0.10 & -0.12 & -0.06 & -0.15 & -0.27 & -0.21 \\
\hline & 1 . & & 1.3 & 1.1 & 1.4 & 1.2 & 1.1 & 1.2 & 1.2 & 1.3 & 1.4 & $1 \cdot 2$ & 1.3 & 1.3 & 1.3 & $1 \cdot 1$ \\
\hline Current weight-for-length $z$-score & & & & & & & & & & & & & & & & \\
\hline Mean & 0.1 & & -0.01 & 0.04 & 0.07 & 0.16 & 0.15 & 0.28 & 0.28 & $0 \cdot 10$ & 0.32 & 0.29 & 0.31 & 0.20 & -0.05 & -0.15 \\
\hline SD & 1. & & 1.3 & 1.3 & 1.7 & 1.4 & 1.3 & $1 \cdot 1$ & 1.1 & 1.4 & 1.1 & 1.3 & 1.3 & 1.1 & 1.0 & 1.3 \\
\hline Number of teeth & & & & & & & & & & & & & & & & \\
\hline Mean & 6. & & $\begin{array}{l}0.5 \\
1.9\end{array}$ & 0.4 & 0.7 & 1.4 & 2.4 & 3.3 & $\begin{array}{r}3.9 \\
2.3\end{array}$ & 5.4 & $\begin{array}{l}7.0 \\
2.9\end{array}$ & $10 \cdot 3$ & $13 \cdot 4$ & $15 \cdot 2$ & $16 \cdot 4$ & $18 \cdot 2$ \\
\hline $\begin{array}{l}\text { SD } \\
\text { Girlst }\end{array}$ & $1442^{6}$ & 38.1 & $\begin{array}{r}1.9 \\
51.4\end{array}$ & $\begin{array}{r}1.3 \\
47.0\end{array}$ & $\begin{array}{r}1.5 \\
48.1\end{array}$ & $\begin{array}{r}2.0 \\
48.5\end{array}$ & 51.3 & $\begin{array}{r}2.5 \\
46.7\end{array}$ & $\begin{array}{r}2.3 \\
42.9\end{array}$ & $\begin{array}{r}2.5 \\
13.8\end{array}$ & 2.9 & & & & $2 \cdot 7$ & $2 \cdot 4$ \\
\hline $\begin{array}{l}\text { GirisT } \\
\text { Birth order }\end{array}$ & 1442 & 48.1 & 51.4 & $4 / .0$ & $48 \cdot 1$ & & & $46 \cdot 1$ & $42 \cdot 9$ & 43.8 & 49.5 & $50 \cdot 2$ & $50 \cdot 0$ & $48 \cdot 3$ & $49 \cdot 3$ & $40 \cdot 0$ \\
\hline First born & 2290 & $77 \cdot 1$ & $74 \cdot 3$ & $84 \cdot 3$ & $75 \cdot 1$ & $76 \cdot 2$ & $72 \cdot 7$ & $78 \cdot 2$ & $77 \cdot 7$ & 74.6 & $77 \cdot 1$ & $76 \cdot 0$ & 73.0 & $79 \cdot 1$ & $79 \cdot 2$ & $81 \cdot 2$ \\
\hline Gagging & & & & & & & & & & & & & & & & \\
\hline Sometimes/often & 645 & $21 \cdot 8$ & 27.5 & 30.9 & 29.7 & $32 \cdot 1$ & $27 \cdot 4$ & 19.5 & $24 \cdot 7$ & $24 \cdot 6$ & $18 \cdot 9$ & 17.1 & 13.4 & 14.9 & 9.9 & 14.0 \\
\hline Rarely & 1050 & $35 \cdot 6$ & 31.9 & $32 \cdot 6$ & $42 \cdot 7$ & 38.0 & $37 \cdot 1$ & 39.5 & $36 \cdot 8$ & $37 \cdot 3$ & $42 \cdot 7$ & 31.3 & 35.2 & $35 \cdot 1$ & 24.4 & 24.0 \\
\hline Never & 1258 & $42 \cdot 6$ & $40 \cdot 6$ & 36.5 & $27 \cdot 6$ & 29.9 & 35.5 & 41.0 & 38.5 & 38.1 & 38.4 & 51.6 & 51.4 & $50 \cdot 0$ & $65 \cdot 7$ & 62.0 \\
\hline Sitting alone & & & & & & & & & & & & & & & & \\
\hline Never/rarely & 394 & $13 \cdot 2$ & $70 \cdot 2$ & 57.1 & $33 \cdot 1$ & $16 \cdot 1$ & 6.4 & 0.5 & $2 \cdot 4$ & 0.0 & 0.3 & 0.0 & 0.0 & 0.0 & 0.0 & 0.0 \\
\hline Sometimes/often & 2599 & $86 \cdot 8$ & 29.8 & $42 \cdot 9$ & $66 \cdot 9$ & 83.9 & $93 \cdot 6$ & 99.5 & $97 \cdot 6$ & 100.0 & 99.7 & $100 \cdot 0$ & $100 \cdot 0$ & 100.0 & 100.0 & $100 \cdot 0$ \\
\hline Eating with fingers & & & & & & & & & & & & & & & & \\
\hline Never/rarely & 1368 & $46 \cdot 0$ & $92 \cdot 8$ & $92 \cdot 8$ & 89.5 & 83.4 & $70 \cdot 3$ & $56 \cdot 7$ & $53 \cdot 3$ & $30 \cdot 6$ & 25.5 & $12 \cdot 2$ & $9 \cdot 4$ & $11 \cdot 2$ & 8.4 & $13 \cdot 6$ \\
\hline Sometimes/often & 1605 & 54.0 & 7.2 & 7.2 & 10.5 & $16 \cdot 6$ & 29.7 & $43 \cdot 3$ & $46 \cdot 7$ & 69.4 & 74.5 & 87.8 & $90 \cdot 6$ & 88.8 & 91.6 & 86.4 \\
\hline Self-feeding with a fork & & & & & & & & & & & & & & & & \\
\hline Never/rarely & 2110 & $72 \cdot 0$ & 98.6 & $100 \cdot 0$ & $100 \cdot 0$ & 99.6 & 99.4 & 98.9 & $96 \cdot 4$ & 98.5 & 87.1 & $54 \cdot 6$ & 29.9 & $16 \cdot 3$ & 3.9 & 2.4 \\
\hline Sometimes/often & 827 & 28.0 & 1.4 & 0.0 & 0.0 & 0.4 & 0.6 & 1.1 & 3.6 & 1.5 & 12.9 & 45.4 & $70 \cdot 1$ & 83.7 & $96 \cdot 1$ & 97.6 \\
\hline Feeding practices & & & & & & & & & & & & & & & & \\
\hline Any breast-feeding & 1886 & $62 \cdot 9$ & $55 \cdot 6$ & $62 \cdot 9$ & $63 \cdot 8$ & $67 \cdot 1$ & $63 \cdot 6$ & $63 \cdot 1$ & 62.5 & 63.5 & $56 \cdot 5$ & $63 \cdot 4$ & $65 \cdot 0$ & 67.4 & 64.0 & 64.8 \\
\hline $\begin{array}{l}\text { Age of CF } \\
\text { Mean }\end{array}$ & 4. & & 4.1 & 4.4 & 4.7 & 4.8 & 4.9 & 4.9 & 4.8 & 4.9 & 5.0 & 5.1 & 5.0 & 5.0 & 5.2 & $5 \cdot 1$ \\
\hline $\begin{array}{l}\text { VD } \\
\text { SD }\end{array}$ & 1 . & & 0.4 & 0.6 & 0.7 & 0.8 & 0.9 & 0.8 & 0.8 & 1.2 & 1.0 & 1.2 & 1.1 & 1.1 & 1.7 & 1.7 \\
\hline
\end{tabular}




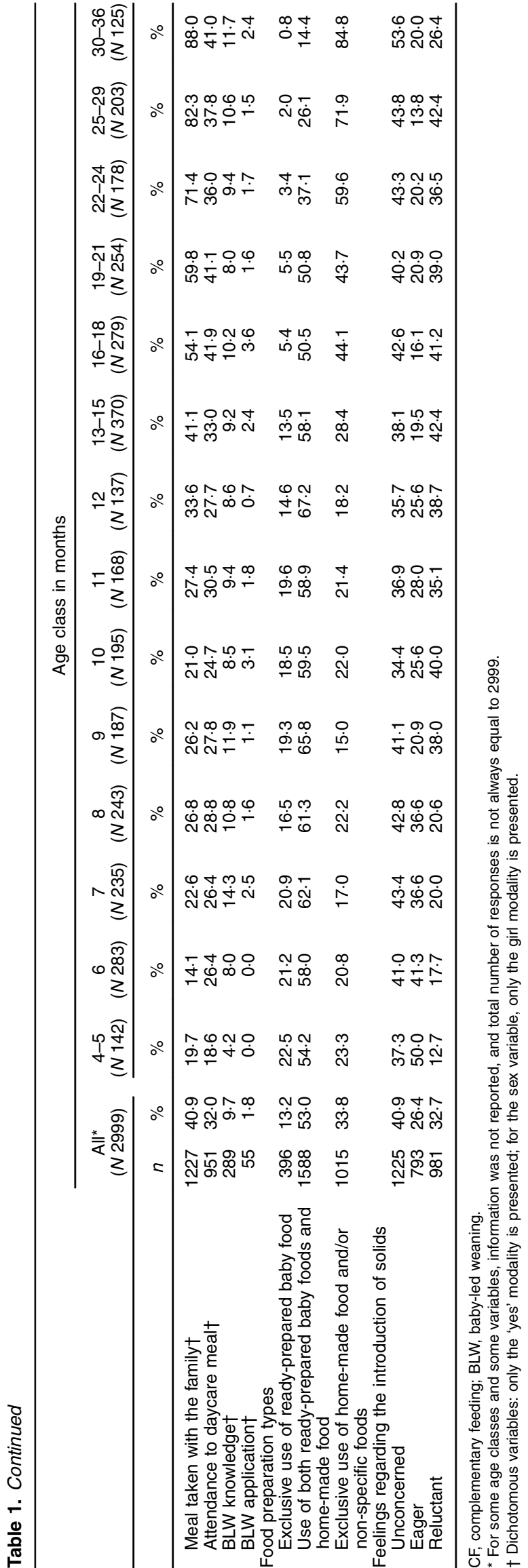

\section{Associations between the food texture exposure scores and maternal characteristics}

Concerning the mother's characteristics, the multivariate analyses showed that at $6,10,11,13-15$ and 25-29 months, young mothers exposed their child slightly more to food texture combinations than older mothers (Table 3 and Fig. 3). Higher education level was never significantly associated with TextExp score but was forced in all multivariate models, as it is an important indicator of social differences.

\section{Associations between the food texture exposure scores and children's characteristics}

The number of teeth was strongly positively associated with TextExp score from $4-5$ to 8 months (all $P<0.0001$ ) and less strongly at 12 months $(P=0 \cdot 02)$ and $22-24$ months $(P=0 \cdot 002)$. A negative effect of gagging was observed at 16-18 and 25-29 months: children who sometimes/often had a gag reflex were less exposed to food textures compared with those who never had a gag reflex. Not being able to sit up alone was associated with a lower exposure to textures at $6(P=0.02)$ and 7 months $(P=0.003)$. Eating with fingers rarely or never was associated with a lower exposure to textures than frequent eating with fingers from the first year until mid-second year (significant effect at all ages from 4-5 months to 19-21 months, except at 16-18 months). Similarly, not or rarely self-feeding with a fork was associated with a lower exposure to textures compared with frequent self-feeding with a fork during the second year (13-15 months until 22-24 months).

\section{Associations between food texture exposure score and feeding practices}

Several feeding practices were significantly associated with TextExp score (Table 3 and Fig. 3). The effect of having ever been breast-fed was inconsistent: it was associated with a lower texture exposure at $4-5$ months $(P=0 \cdot 03)$ but to a higher texture exposure at 11 months $(P<0 \cdot 001)$. The age of $\mathrm{CF}$ was consistently negatively associated with TextExp, between 6 and 19-21 months (except at 13-15 months), which means that children who were introduced to $\mathrm{CF}$ later received less food texture combinations. Considering the food preparation type factor, children of mothers who declared offering exclusively commercial baby foods were exposed to a lower number of food texture combinations at 12 and 13-15 months than children of mothers who declared offering both commercial baby foods and home-made food. In contrast, children of mothers who declared offering only home-made and/ or non-specific foods were exposed to a higher number of food texture combinations than children of mothers who declared offering both commercial baby foods and home-made food at 9 , 13-15, 16-18 and 30-36 months (Fig. 3).

Table 3 and Fig. 3 also showed that children who ate with the family were exposed to more food texture combinations than children who ate only with the caregiver (at 8, 9, 12, 16-18, 22-24 and 25-29 months). At 30-36 months only, children who participated in daycare meals were exposed to more food texture combinations than those who did not (Table 3). 
Table 2. Number of food textures combinations offered to at least $50 \%$ of the population, globally and for each food category*

\begin{tabular}{|c|c|c|c|c|c|c|c|c|c|c|c|c|c|c|c|c|c|c|c|c|c|c|c|c|c|c|c|}
\hline \multirow[b]{4}{*}{ Age (months) } & \multirow{2}{*}{\multicolumn{3}{|c|}{ All food categories }} & \multicolumn{3}{|c|}{$\begin{array}{l}\text { Commercial baby } \\
\text { foods }\end{array}$} & \multicolumn{3}{|c|}{ Vegetables } & \multicolumn{3}{|c|}{$\begin{array}{l}\text { Potato and sweet } \\
\text { potato }\end{array}$} & \multicolumn{3}{|c|}{ Fruit } & \multicolumn{2}{|c|}{ Meat } & \multicolumn{2}{|c|}{ Fish } & \multirow{2}{*}{$\frac{\text { Eggs }}{N 3}$} & \multicolumn{3}{|c|}{$\begin{array}{l}\text { Cheese and dairy } \\
\text { products }\end{array}$} & \multicolumn{2}{|c|}{$\begin{array}{l}\text { Cereal-based } \\
\text { foods }\end{array}$} & \multicolumn{2}{|c|}{$\begin{array}{c}\text { Miscellaneous } \\
\text { savoury } \\
\text { and sweet foods }\end{array}$} \\
\hline & & & & & $N 16$ & & & $N 49$ & & & $N 5$ & & & $N 42$ & & & 13 & $N$ & 15 & & & $N 13$ & & & & & \\
\hline & $\mathrm{T} 1$ & T2 & T3 & $\mathrm{T} 1$ & $\mathrm{~T} 2$ & Т3 & $\mathrm{T} 1$ & $\mathrm{~T} 2$ & Т3 & $\mathrm{T} 1$ & $\mathrm{~T} 2$ & T3 & $\mathrm{T} 1$ & T2 & T3 & T2 & Т3 & $\mathrm{T} 2$ & Т3 & T2 & $\mathrm{T} 1$ & $\mathrm{~T} 2$ & Т3 & T2 & T3 & $\mathrm{T} 2$ & T3 \\
\hline & $n 38$ & $n 41$ & $n 109$ & $n 10$ & $n 3$ & $n 3$ & $n 13$ & $n 9$ & $n 27$ & $n 2$ & $n 1$ & $n 2$ & $n 9$ & $n 5$ & $n 28$ & $n 2$ & $n 11$ & $n 6$ & $n 9$ & $n 3$ & $n 4$ & $n 3$ & $n 6$ & $n 6$ & $n 11$ & $n 3$ & $n 12$ \\
\hline $4-5$ & 5 & 0 & 0 & 2 & 0 & 0 & 2 & 0 & 0 & 0 & 0 & 0 & 1 & 0 & 0 & 0 & 0 & 0 & 0 & 0 & 0 & 0 & 0 & 0 & 0 & 0 & 0 \\
\hline 6 & 10 & 0 & 0 & 2 & 0 & 0 & 3 & 0 & 0 & 1 & 0 & 0 & 4 & 0 & 0 & 0 & 0 & 0 & 0 & 0 & 0 & 0 & 0 & 0 & 0 & 0 & 0 \\
\hline 7 & 14 & 0 & 0 & 5 & 0 & 0 & 4 & 0 & 0 & 1 & 0 & 0 & 4 & 0 & 0 & 0 & 0 & 0 & 0 & 0 & 0 & 0 & 0 & 0 & 0 & 0 & 0 \\
\hline 8 & 15 & 3 & 0 & 5 & 0 & 0 & 5 & 0 & 0 & 1 & 0 & 0 & 4 & 0 & 0 & 2 & 0 & 1 & 0 & 0 & 0 & 0 & 0 & 0 & 0 & 0 & 0 \\
\hline 9 & 21 & 3 & 0 & 6 & 0 & 0 & 8 & 0 & 0 & 2 & 0 & 0 & 4 & 0 & 0 & 2 & 0 & 1 & 0 & 0 & 1 & 0 & 0 & 0 & 0 & 0 & 0 \\
\hline 10 & 28 & 4 & 2 & 9 & 0 & 1 & 8 & 0 & 0 & 2 & 0 & 0 & 7 & 0 & 0 & 2 & 0 & 1 & 0 & 0 & 2 & 0 & 0 & 1 & 0 & 0 & 1 \\
\hline 11 & 31 & 4 & 3 & 9 & 0 & 1 & 9 & 0 & 0 & 2 & 0 & 0 & 8 & 0 & 0 & 2 & 0 & 1 & 0 & 0 & 3 & 0 & 0 & 1 & 1 & 0 & 1 \\
\hline 12 & 35 & 7 & 6 & 10 & 1 & 1 & 11 & 0 & 0 & 2 & 0 & 0 & 8 & 0 & 1 & 2 & 0 & 1 & 0 & 1 & 4 & 1 & 0 & 1 & 3 & 0 & 1 \\
\hline $13-15$ & 34 & 20 & 14 & 9 & 2 & 1 & 11 & 5 & 0 & 2 & 1 & 0 & 8 & 1 & 3 & 2 & 2 & 2 & 0 & 1 & 4 & 1 & 1 & 5 & 5 & 0 & 2 \\
\hline $16-18$ & 35 & 24 & 28 & 9 & 3 & 1 & 12 & 5 & 5 & 2 & 1 & 1 & 8 & 2 & 6 & 2 & 3 & 2 & 0 & 1 & 4 & 2 & 2 & 6 & 6 & 0 & 4 \\
\hline $19-21$ & 35 & 29 & 40 & 10 & 3 & 2 & 11 & 6 & 5 & 2 & 1 & 2 & 8 & 2 & 11 & 2 & 5 & 2 & 0 & 2 & 4 & 3 & 3 & 6 & 6 & 2 & 6 \\
\hline $22-24$ & 36 & 33 & 64 & 10 & 3 & 2 & 12 & 7 & 13 & 2 & 1 & 2 & 8 & 3 & 18 & 2 & 8 & 3 & 1 & 2 & 4 & 3 & 6 & 6 & 7 & 3 & 7 \\
\hline $25-29$ & 35 & 35 & 79 & 9 & 3 & 3 & 12 & 8 & 17 & 2 & 1 & 2 & 8 & 4 & 22 & 2 & 11 & 3 & 3 & 2 & 4 & 3 & 6 & 6 & 7 & 3 & 8 \\
\hline $30-36$ & 37 & 36 & 90 & 10 & 3 & 3 & 13 & 8 & 19 & 2 & 1 & 2 & 8 & 4 & 26 & 2 & 11 & 4 & 6 & 2 & 4 & 3 & 6 & 6 & 7 & 3 & 10 \\
\hline
\end{tabular}

T1, simple textures (puréed foods); T2, intermediate textures (small cooked pieces); T3, hard and/or large pieces (raw, hard foods in small or big pieces) and double textures. * For each food category, $N$ is the total number of items present in the questionnaire. $n$ gives the number of T1, T2 and T3 items composing $N$. For example: the 'Vegetables' category contains forty-nine food texture combinations in total (13
T1, 9 T2 and 27 T3). 
(a)
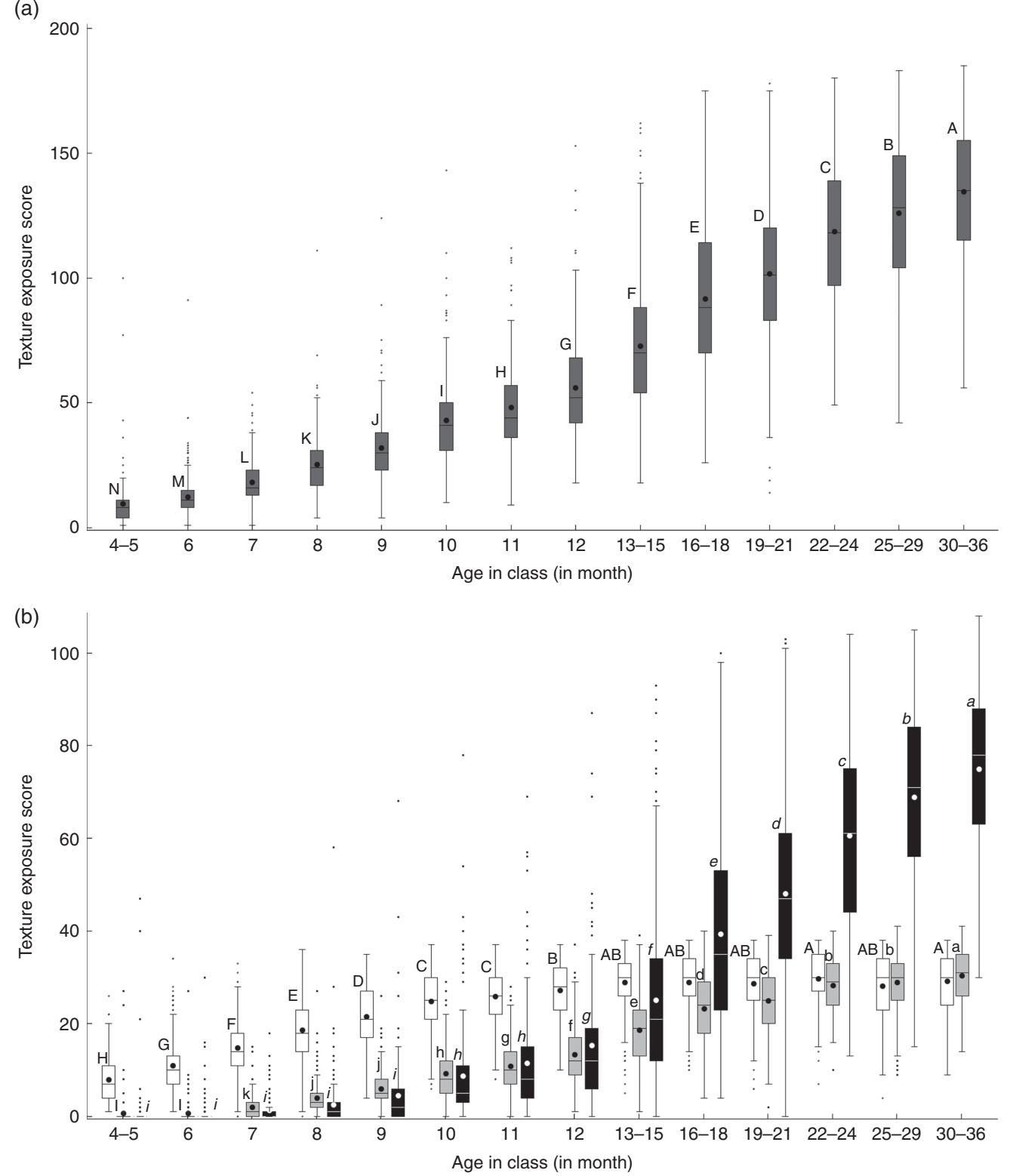

Fig. 2. (a) and (b) Distribution of food texture exposure scores (globally (a) and by texture levels (b)) by age class from 4-5 months to $30-36$ months. Values are shown as box-plots in which the horizontal lines indicate the 25th, 50th (i.e. median) and 75th percentiles. $\square$, T1: simple textures; $\square$, T2: cooked pieces + soft foods; $\square$, T3: hard and/or large pieces + double textures.

Mothers' feelings with regard to the introduction of solid foods were often associated with texture exposure score, mostly from the second year onwards (Table 3 and Fig. 3). Indeed, mothers who were reluctant to introduce food pieces exposed their child to less food texture combinations than unconcerned mothers, especially during the second year (at 11, 13-15, 16-18 and 19-21 months).

\section{Discussion}

This study aimed to describe the practices of food texture introduction throughout the CF period and to identify the associated factors for these practices.
In the studied population, the age of $\mathrm{CF}$ introduction (4.9 (SD 1.1) months) was similar to observations in the representative French samples (5.0 and 5.2 (SD 1.2) months for Epifane (Epidémiologie en France de l'alimentation et de l'état nutritionnel des enfants pendant leur première année de vie) and ELFE (Etude Longitudinale Française depuis l'Enfance), respectively) ${ }^{(23,25)}$. Mothers from our sample followed the French national recommendations with regard to the timing of the introduction of the different food categories: vegetables, potato and fruits were first introduced between 4 and 6 months, followed by meat, fish, dairy products and cereals at 8-9 months ${ }^{(15)}$. These findings are consistent with the results obtained from a nation-wide birth cohort (EPIFANE cohort), which reported that at 12 months more than 
Table 3. Associations between food texture exposure score and maternal and infant characteristics and feeding practices from multiple linear regression models performed by age class $(P$ values of the effects $\S)$

\begin{tabular}{|c|c|c|c|c|c|c|c|c|c|c|c|c|c|c|}
\hline Age groups (in months) & $4-5$ & 6 & 7 & 8 & 9 & 10 & 11 & 12 & $13-15$ & $16-18$ & $19-21$ & $22-24$ & $25-29$ & $30-36$ \\
\hline$n$ & 142 & 283 & 235 & 243 & 187 & 195 & 168 & 137 & 370 & 279 & 254 & 178 & 203 & 125 \\
\hline \multicolumn{15}{|l|}{ Maternal characteristics } \\
\hline Age & $-\dagger$ & $0.03^{*}$ & $-\dagger$ & $-\dagger$ & 0.11 & $0.01^{*}$ & $0.002^{*}$ & $-\dagger$ & $0.007^{*}$ & $-\dagger$ & $-\dagger$ & $-\dagger$ & $0.02^{*}$ & $-\dagger$ \\
\hline Higher education level & 0.71 & 0.80 & 0.41 & 0.92 & 0.40 & 0.73 & 0.87 & 0.47 & 0.69 & 0.68 & 0.47 & $0 \cdot 16$ & 0.90 & 0.66 \\
\hline \multicolumn{15}{|l|}{ Children's characteristics } \\
\hline Number of teeth & $<0.001^{*}$ & $<0.001^{\star}$ & $<0.001^{*}$ & $<0.001^{*}$ & $-\dagger$ & $-\dagger$ & $-\dagger$ & $0.02^{*}$ & $-\dagger$ & 0.19 & $-\dagger$ & $0.002^{*}$ & 0.11 & $-\dagger$ \\
\hline Gagging & $-\dagger$ & $-\dagger$ & $-\dagger$ & $-\dagger$ & $-\dagger$ & $-\dagger$ & $-\dagger$ & $-\dagger$ & 0.28 & $0.002^{*}$ & $-\dagger$ & $-\dagger$ & $0.001^{*}$ & $-\dagger$ \\
\hline Sitting up alone & 0.09 & $0.02^{*}$ & $0.003^{*}$ & $-\dagger$ & $-\dagger$ & $-\ddagger$ & $-\ddagger$ & $-\ddagger$ & $-\ddagger$ & $-\ddagger$ & $-\ddagger$ & $-\ddagger$ & $-\ddagger$ & $-\ddagger$ \\
\hline Eating with fingers & $0.001^{*}$ & $0.046^{*}$ & $0.003^{*}$ & $0.01^{*}$ & $<0.001^{*}$ & $<0.001^{*}$ & $0.005^{\star}$ & $<0.001^{*}$ & $<0.001^{*}$ & 0.08 & $0.04^{*}$ & $-\dagger$ & $-\dagger$ & $-\dagger$ \\
\hline Self-feeding with a fork & $-\ddagger$ & $-\ddagger$ & $-\ddagger$ & $-\ddagger$ & $-\ddagger$ & $-\ddagger$ & $-\ddagger$ & $-\ddagger$ & $<0.001^{*}$ & $<0.001^{*}$ & $<0.001^{\star}$ & $<0.001^{*}$ & $<0.001^{*}$ & $-\ddagger$ \\
\hline \multicolumn{15}{|l|}{ Feeding practices } \\
\hline Any breast-feeding & $0.03^{\star}$ & $-\dagger$ & $-\dagger$ & $-\dagger$ & $-\dagger$ & $-\dagger$ & $<0.001^{*}$ & $-\dagger$ & 0.16 & $-\dagger$ & $-\dagger$ & $-\dagger$ & 0.053 & $-\dagger$ \\
\hline Age of $\mathrm{CF}$ & $-\dagger$ & $<0.001^{\star}$ & $<0.001^{*}$ & $<0.001^{*}$ & $0.001^{*}$ & $0.03^{*}$ & $0.046^{*}$ & $<0.001^{\star}$ & $-\dagger$ & $<0.001^{*}$ & $0.005^{\star}$ & $-\dagger$ & 0.53 & $-\dagger$ \\
\hline Food preparation types & $-\dagger$ & $-\dagger$ & $-\dagger$ & 0.059 & $0.009^{\star}$ & $-\dagger$ & 0.31 & $<0.001^{\star}$ & $<0.001^{*}$ & $0.002^{*}$ & 0.13 & 0.43 & 0.14 & $0.02^{*}$ \\
\hline Meal taken with family & 0.12 & $-\dagger$ & 0.07 & $0.02^{*}$ & $0.03^{\star}$ & $-\dagger$ & $-\dagger$ & $0.001^{*}$ & 0.11 & $0.008^{*}$ & 0.48 & $<0.001^{*}$ & 0.04 & 0.18 \\
\hline Meal taken at daycare & $-\dagger$ & $-\dagger$ & $-\dagger$ & $-\dagger$ & $-\dagger$ & $-\dagger$ & $-\dagger$ & $-\dagger$ & $-\dagger$ & $-\dagger$ & $-\dagger$ & $-\dagger$ & $-\dagger$ & $0.01^{*}$ \\
\hline Feelings regarding the introduction of solids & $-\dagger$ & $-\dagger$ & $-\dagger$ & $-\dagger$ & $-\dagger$ & $-\dagger$ & $0.03^{*}$ & $-\dagger$ & $0.004^{*}$ & $<0.001^{*}$ & $0.02^{*}$ & 0.15 & 0.17 & $0.003^{*}$ \\
\hline Model R2 & 0.73 & 0.32 & 0.23 & 0.22 & 0.32 & 0.15 & 0.29 & 0.37 & 0.38 & 0.40 & 0.26 & 0.31 & 0.33 & 0.24 \\
\hline
\end{tabular}

$\mathrm{CF}$, complementary feeding.

"Significant $P$ values $(P<0.05)$.

† Not tested because variable was not significant in bivariate analyses.

TNot tested because sample size was insufficient for some modalities.

$\S \beta$ Values are reported in Fig. 2(a) and (b). 

Mother's age -
Number of teeth -
Gagging-never -
Gagging-rarely -
sometimes/often -
lone-never/rarely -
-sometimes/often -
gers-never/rarely -

Eating with fingers-never/rarely - H

Self-feeding with a fork-never/rarely Self-feeding with a fork-sometimes/often [Breast-feeding-no - H Breast-feeding-yes Age of $\mathrm{CF}$

[Food preparation types-exclusively baby foods Food preparation types-home made/family foods Food preparation types -baby foods/home made [Meal taken with family-no Meal taken with family-yes [Meal taken at daycare-no Meal taken at daycare-yes [ Feelings reg. solids introduction-reluctant Feelings reg. solids introduction-eager Feelings reg. solids introduction-unconcerned
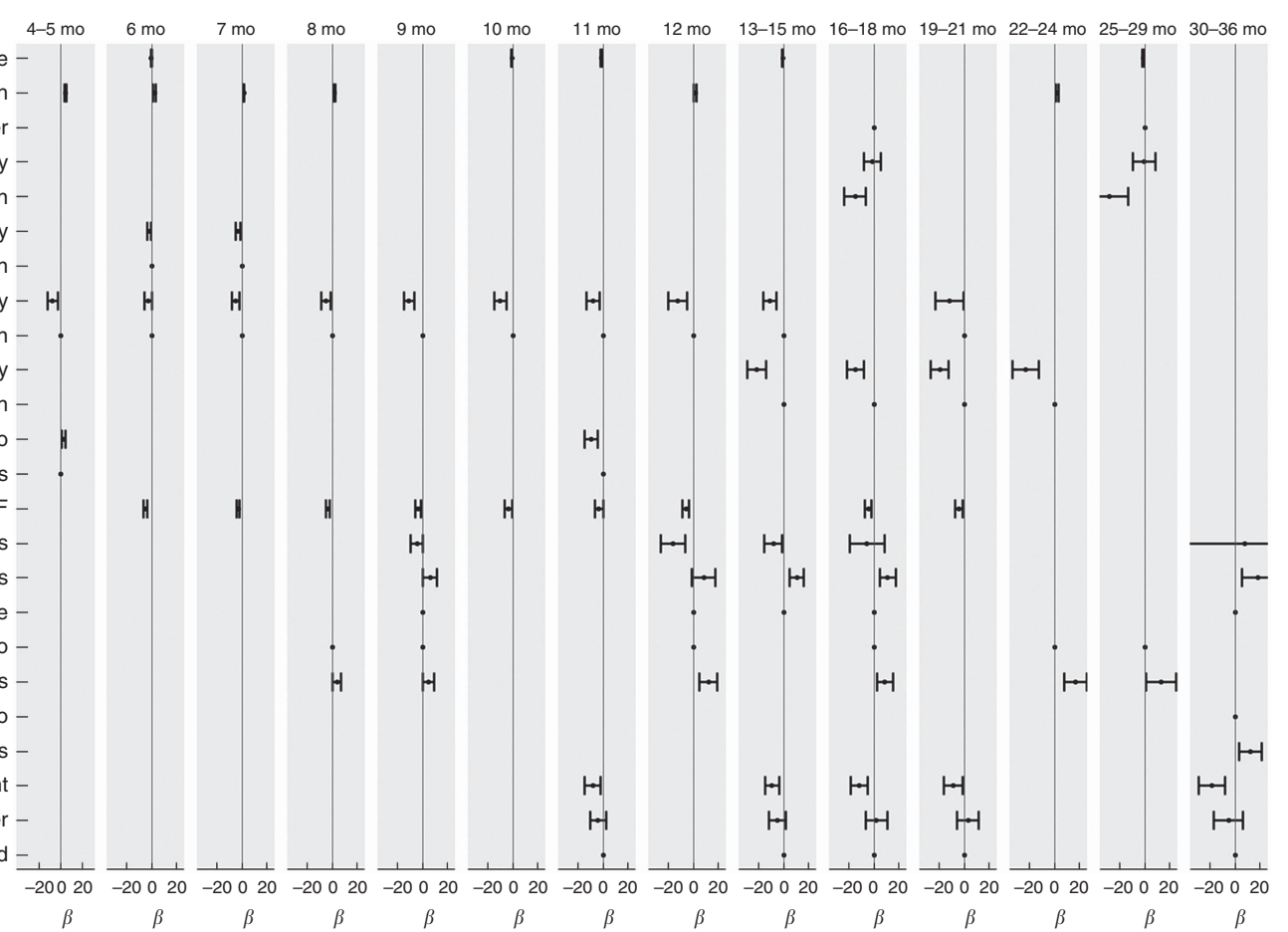

Fig. 3. $\beta$-Values (and $95 \% \mathrm{Cl}$ ) for the associations between food texture exposure score and maternal and children characteristics and feeding practices, calculated from multiple linear regression models performed by age class. Only $\beta$-values from significant effects as reported in Table 3 are shown here. Dots indicate modality of reference for each studied factor. CF, complementary feeding.

$92 \%$ of infants frequently consumed vegetables, fruits, meat, fish and cereal products ${ }^{(23)}$. Concerning the type of foods used, here the percentage of mothers who never offered baby foods (33.8\%) is higher than that reported in other studies (Committee on Nutrition of the French Society of Paediatrics: $24 \%{ }^{(31)}$; Nutribebe survey: $\left.25 \%^{(32)}\right)$. The Nutribebe survey also mentioned that commercial baby food products were practically not offered after 18 months and that the use of home-made food increased particularly after 12 months $^{(32)}$; this was also observed in our study.

Concerning the introduction of texture, our results indicated that over the first year infants were mainly exposed to pureed foods and that this type of texture was still present in the children's diet at 30-36 months. A similar observation was made in the Nutribebe survey, which showed that, between 8 and 11 months, $47 \%$ of the infants consumed purées ${ }^{(21)}$. Our survey provides additional insight with regard to the introduction of solid foods. We observed that pieces were mainly introduced from the end of the first year onwards. This timing is late compared with the age span advised in the ESPGHAN recommendations ${ }^{(14)}$, which recommends to give lumpy foods at 8-10 months at the latest. Our results also showed that, for the fruit category only, raw pieces were introduced at 12 months, before cooked pieces, which were not offered before 16-18 months. This finding suggests that preparing cooked pieces of fruits for children is not a widespread practice. With regard to food texture progression, the French recommendations are not very specific, and just recommend that the texture should evolve according to the child's chewing skills ${ }^{(15)}$. This lack of specific information could result in conservative attitudes and practices towards food texture introduction. Our data on when which foods and textures are introduced revealed that the age of 13-15 months corresponds to a transitional period in which cooked and raw pieces are introduced. This period coincides with important milestones in the development of a child's feeding and motor skills ${ }^{(33,34)}$.

We observed that children's exposure to texture was associated with both children's characteristics and maternal feeding practices. Concerning children's characteristics, texture exposure was associated mostly with number of teeth and the ability to eat with fingers or with a fork. The number of teeth was positively associated with exposure to textures for several age classes during the first 2 years, in particular up to 8 months. The ability to sit up alone was only associated with a higher exposure at young ages (6-7 months). Moreover, signs that the child is acquiring feeding autonomy (eating with fingers during the first year or with a fork from the beginning of the second year) were also associated with exposure to textures. Altogether, these data suggest that mothers are influenced by a variety of indicators of readiness for the introduction of solid textures: presence of teeth, ability to sit alone and ability to self-feed, with fingers or a fork, which evolve across development. Gagging frequency reported by mothers in our study was within the frequency range observed from video analysis of 8- to 9month-old children eating pieces ${ }^{(7)}$. In contrast to what could be expected, gagging was only associated with texture exposure during the second year and thus does not appear as a strong predictor, although it concerned $22 \%$ of the children.

Concerning feeding practices, children's exposure to textures was found to be mainly associated with the type of food preparation used by their parents, mainly during the second year. In particular, the use of home-made foods or non-specific foods, declared by mothers, was associated with a higher TextExp. From 12 months, parents started to offer cooked 
pieces and raw or hard foods to children. These food textures are likely to come from home-made and non-specific foods. Most commercial baby foods intended for infants older than 8 months are composed of purées that contain soft pieces; although they differ in particle size ${ }^{(6)}$, and are more likely to be uniform in texture than home-made foods. Thus, the diversity of the food textures offered in commercial baby foods could be more limited than in home-made foods or non-specific foods.

Moreover, children taking their meals with the family were more likely to be exposed to more food textures, mainly during the second year. How mothers and other family members interact with the child during mealtime might modulate the child's feeding experiences. More specifically, the child can imitate the adults or siblings' eating behaviours as observational learning is an important way for infants and toddlers to learn about food $^{(35)}$. This way, the transition to adult foods can be stimulated, which increases the exposure to more solid foods and more food texture combinations.

We investigated also the effect of any breast-feeding. We observed an inconsistent relationship between breast-feeding and the TextExp scores: a negative relation at $4-5$ months, a positive relation at 11 months and no significant relations at the other ages. We conclude that there is no relation between breastfeeding and TextExp. This does not exclude the possibility of a relation between breast-feeding duration and TextExp; however, breast-feeding duration was not collected in our study.

Our results showed that an earlier initiation of CF was associated with a higher TextExp score, especially for young children (until 19-21 months). A possible explanation is that an earlier initiation of CF could lead to an earlier introduction of solid foods and more complex textures. Alternatively, infants who receive $\mathrm{CF}$ earlier could be developmentally more advanced and could make the next steps in texture progression earlier. There could also be a link to mothers' attitudes and characteristics. For example, we found at some ages that the mothers' age was negatively associated with TextExp, which means that younger mothers gave more food texture combinations to their infants. In the literature, maternal characteristics were studied in relation to the age of introducing CF. In particular, younger, less educated mothers were more likely to initiate CF before 4 months than older and more educated mothers ${ }^{(25,36,37)}$, which would explain why there is an effect of both maternal age and introduction of CF on TextExp. However, this should not be interpreted as a reason for introducing complementary foods before the age of 4 months

We seldom observed an association between the type of information sources consulted on $\mathrm{CF}$ and the texture exposure. Thus, we did not include this factor in the multivariate analysis. This limited effect of the source of information on exposure to food texture could be because the available information on food texture introduction is quite limited in France. Indeed, a detailed analysis of the current national or international recommendation performed by Schwartz et al. ${ }^{(2)}$ highlighted the under-representation of the texture topic in France compared with other countries, such as the UK, for example.

We found that mothers who were reluctant to introduce food pieces exposed their infants less to different textures. This reluctance could be explained by the fear of choking and could delay the introduction of food pieces. Indeed, a focus group studying CF practices of French mothers revealed that the fear of choking was prominently present when addressing the role of texture in $\mathrm{CF}^{(28)}$. In 2012, the number of reported deaths due to home and leisure injury among infants under 1 year of age in France was 27 $(2 \cdot 1 / 100000)$, sixteen of which were due to choking; they were mostly caused by the ingestion of foods ${ }^{(38)}$. Providing adequate advice on the prevention of choking risks and training parents on how to apply first aid could help them feel more confident with regard to the introduction of food texture combinations.

There are several limitations in the current survey, which must be considered when evaluating the findings. First, we used a convenience sample, limiting the degree to which the results can be assumed to represent the French population as a whole. The main differences between the studied sample and the general population relate to parity and education level. Compared with the national perinatal survey and populations included in French national-based cohorts (EPIFANE, ELFE), mothers involved in our study were more often primiparous (first birth rank was $77 v .40-44 \%)^{(24,26,40)}$ and more educated $(65 \%$ had an education level higher than highschool diploma $v .52 \%$ in the general French population in $2016)^{(40)}$. Despite these socio-demographic differences, general feeding practices of our mothers were comparable to those of the general population with regard to age of $\mathrm{CF}$ introduction and type of CF food introduced. As our database was part of a baby food brand web information programme, we expected that interviewed mothers would more likely be consumers of commercial baby food products. This did not seem to be the case as discussed earlier. In addition, the number of children per age class were not equal; in particular, children from younger age classes were over-represented. Moreover, data from 4- to 5-month-old children were collected only for those who were already introduced to complementary foods and therefore they should not be considered as representative of all infants of this age in the general population.

Second, the analysis of the influence of practices was based on self-reports by mothers, which could have compromised their reliability. Although all parents were asked to refer to the current period to answer the questionnaire, it may be that parents of older children had incorporated practices covering a longer period, which may have led to an overestimation of the number of textures their children were exposed to.

The texture level assignment that we used for classifying the food texture combinations into three levels was based on the literature ${ }^{(2,6,28,30)}$ and knowledge of the authors of this article but it was not very specific. The texture of food is multidimensional and involves a range of characteristics, such as the pieces size, shape and consistency ${ }^{(39)}$. However, as we did not have information about the usual brands and cooking methods, we could not classify food textures more precisely.

Previous research highlighted the role of repeated exposure to flavour and taste in the development of food acceptance during the $\mathrm{CF}$ period $^{(40-42)}$. So far, research on the effect of previous exposure on texture acceptance in babies has been studied only once: Blossfeld et al. ${ }^{(8)}$ found that the acceptance of chopped carrots by infants of 12 months was determined mainly by their previous experience with chopped textures, but 
this is the only study so far on this topic. Further research is therefore needed to study the relationship between food texture exposure and acceptance; in particular, it should be explored how texture should be introduced and progressed to make sure that children accept a greater number of different and more complex textures, and the effect of this on later healthy food preferences and eating habits.

\section{Conclusions}

This is the first survey conducted in France that provides detailed insight on food texture introduction during the $\mathrm{CF}$ period. Our study shows that over the first year of a child's life children were mainly fed puréed texture and that exposure to pieces slightly increased with age. Soft and small pieces were introduced between 6 and 22 months, whereas hard/large pieces were mainly introduced from 13 months on.

Factors such as the number of teeth and maternal feeding practices (earlier introduction to complementary foods, use of home-made foods, letting the child have meals with the family, autonomous eating during a meal) were associated with a higher TextExp. These new insights provide relevant information to understand factors influencing food texture introduction and ultimately acceptance during a critical period for the development of healthy eating habits.

\section{Acknowledgements}

The authors acknowledge the families of the children who answered this survey.

This research was supported by Blédina SA (Blédina is a supplier of baby food products), the Research and Technology National Association (ANRT), the Conseil Régional Bourgogne, Franche-Comté (PARI grant) and the FEDER (European Funding for Regional Economical Development).

L. D., C. T., A. M., H. W., M. D. and S. N. designed the research. E. K., L. D., C. T. and S. N. designed the analyses, which were performed by E. K., S. N. and L. D. L. D., E. K., C. T. and S. N. analysed and interpreted the results. A. M., H. W. and M. D. contributed to the interpretation of the results. L. D. wrote the initial paper, which was then critically reviewed by C. T. and S. N., and then revised by C. T., A. M., H. W., M. D. and S. N. L. D., C. T., A. M., H. W., M. D. and S. N. had primary responsibility for the final content. All of the authors are responsible for the study findings. All of the authors read and approved the final manuscript.

L. D., A. M. and M. D. are employees of Blédina. H. W. is an employee of Danone Nutricia Research.

\section{Supplementary material}

For supplementary material/s referred to in this article, please visit https://doi.org/10.1017/S0007114518002386

\section{References}

1. Harris G \& Coulthard H (2016) Early eating behaviours and food acceptance revisited: breastfeeding and introduction of complementary foods as predictive of food acceptance. Curr Obes Rep 5, 113-120.

2. Schwartz C, Scholtens P, Lalanne A, et al. (2011) Development of healthy eating habits early in life. Review of recent evidence and selected guidelines. Appetite 57, 796-807.

3. Lundy B, Field T, Carraway K, et al. (1998) Food texture preference in infants versus toddlers. Early Child Dev Care 146, 69-85.

4. Szczesniak AS (1972) Consumer awareness of and attitudes to food texture. II. Children and teenagers. J Texture Stud 3, 206-217.

5. Le Reverend BJD, Edelson LR \& Loret C (2014) Anatomical, functional, physiological and behavioural aspects of the development of mastication in early childhood. Br J Nutr 111, 403-414.

6. Nicklaus S, Demonteil L \& Tournier C (2015) Modifying the texture of foods for infants and young children. In Modifying Food Texture Volume 2: Sensory Analysis, Consumer Requirements and Preferences, pp. 187-222 [J Chen and A Rosenthal, editors]. Cambridge: Woodhead Publishing Limited.

7. da Costa SP, Remijn L, Weenen H, et al. (2017) Exposure to texture of foods for 8-month-old infants: does the size of the pieces matter? J Texture Stud 48, 534--540.

8. Blossfeld I, Collins A, Kiely M, et al. (2007) Texture preferences of 12-month-old infants and the role of early experiences. Food Qual Pref 18, 396-404.

9. Northstone K, Emmett P, Nethersole F, et al. (2001) The effect of age of introduction to lumpy solids on foods eaten and reported feeding difficulties at 6 and 15 months. J Hum Nutr Diet 14, 43-54.

10. Coulthard H, Harris G \& Emmett P (2009) Delayed introduction of lumpy foods to children during the complementary feeding period affects child's food acceptance and feeding at 7 years of age. Mat Child Nutr 5, 75-85.

11. Harris G \& Mason S (2017) Are there sensitive periods for food acceptance in infancy? Curr Nutr Rep 6, 190-196.

12. World Health Organization (2003) Complementary Feeding: Report of the Global Consultation, and Summary of Guiding Principles for Complementary Feeding of the Breastfed Child. Geneva: WHO.

13. European Food Safety Agency (2009) Scientific opinion on the appropriate age for introduction of complementary feeding of infants. EFSA J 7, 1423-1461.

14. Fewtrell M, Bronsky J, Campoy C, et al. (2017) Complementary feeding: a position paper by the European Society for Paediatric Gastroenterology, Hepatology, and Nutrition (ESPGHAN) committee on nutrition. J Pediatr Gastroenterol Nutr 64, 119-132.

15. INPES (Institut National de Prévention et d'Education pour la Santé) (2005) PNNS - La santé vient en mangeant - Le guide parents $0-3$ ans (Health is Through Eating. O-3 Years Parent Guide). Paris: Institut National de Prévention et d'Education pour la Santé.

16. Maier A, Chabanet C, Schaal B, et al. (2007) Effects of repeated exposure on acceptance of initially disliked vegetables in 7-month old infants. Food Qual Pref 18, 1023-1032.

17. Sakashita R, Inoue $N \&$ Tatsuki $T$ (2003) Selection of reference foods for a scale of standards for use in assessing the transitional process from milk to solid food in infants and preschool children. Eur J Clin Nutr 57, 803-809.

18. Cameron SL, Heath ALM \& Taylor RW (2012) How feasible is baby-led weaning as an approach to infant feeding? A review of the evidence. Nutrients $\mathbf{4}, 1575-1609$. 
19. Cichero J (2016) Introducing solid foods using baby-led weaning vs. spoon-feeding: a focus on oral development, nutrient intake and quality of research to bring balance to the debate. Nutr Bull 41, 72-77.

20. Morison BJ, Taylor RW, Haszard JJ, et al. (2016) How different are baby-led weaning and conventional complementary feeding? A cross-sectional study of infants aged 6-8 months. BMJ Open 6, e010665.

21. Enquête Nutri-Bébé (Nutri-Bébé Survey) (2013) L'enquête Nutri-Bébé 2013. http://nutri-bebe-sfae.com (accessed September 2015).

22. Betoko A, Charles MA, Hankard R, et al. (2013) Infant feeding patterns over the first year of life: influence of family characteristics. Eur J Clin Nutr 67, 631-637.

23. Boudet-Berquier J, Salanave B, de Launay C, et al. (2017) Introduction of complementary foods with respect to French guidelines: description and associated socio-economic factors in a nationwide birth cohort (Epifane survey). Matern Child Nutr 13, 12339.

24. Yuan WL, Lange C, Schwartz C, et al. (2016) Infant dietary exposures to sweetness and fattiness increase during the first year of life and are associated with feeding practices. $J$ Nutr 146, 2334-2342.

25. Bournez M, Ksiazek E, Wagner S, et al. (2017) Factors associated with the introduction of complementary feeding in the French ELFE cohort study. Matern Child Nutr 14, e12536.

26. Brown A \& Lee M (2011) A descriptive study investigating the use and nature of baby-led weaning in a UK sample of mothers. Matern Child Nutr 7, 34-37.

27. Marduel Boulanger A \& Vernet M (2018) Introduction of new food textures during complementary feeding: observations in France. Arch Pediatr 25, 6-12.

28. Schwartz C, Madrelle J, Vereijken C, et al. (2013) Complementary feeding and "donner les bases du goût" (providing the foundation of taste). A qualitative approach to understand weaning practices, attitudes and experiences by French mothers. Appetite 71, 321-331.

29. Sakashita R, Inoue N \& Kamegai T (2004) From milk to solids: a reference standard for the transitional eating process in infants and preschool children in Japan. Eur J Clin Nutr 58, 643-653.
30. Lange C, Visalli M, Jacob S, et al. (2013) Maternal feeding practices during the first year and their impact on infants' acceptance of complementary food. Food Qual Pref 29, 89-98.

31. Ghisolfi J, Bocquet A, Bresson JL, et al. (2013) Processed baby foods for infants and young children: a dietary advance? A position paper by the Committee on Nutrition of the French Society of Paediatrics. Arch Pediatr 20, 523-532.

32. Bocquet A \& Vidailhet M (2015) Nutri-Bébé 2013 study part 2. How do French mothers feed their young children? Arch Pediatr 22, Suppl. 1, 10S7-10S9.

33. Stevenson RD \& Allaire JH (1991) The development of normal feeding and swallowing. Pediatr Clin North Am 38, 1439-1453.

34. Delaney AL \& Arvedson JC (2008) Development of swallowing and feeding: prenatal through first year of life. Dev Disab Res Rev 14, 105-117.

35. Mura Paroche M, Caton SJ, Vereijken CMJL, et al. (2017) How infants and young children learn about food: a systematic review. Front Psychol 8, 1046.

36. Kronborg H, Foverskov E \& Væth M (2014) Predictors for early introduction of solid food among Danish mothers and infants: an observational study. BMC Pediatr 14, 243.

37. Schiess S, Grote V, Scaglioni S, et al. (2010) Introduction of complementary feeding in 5 European countries. $J$ Pediatr Gastroenterol Nutr 50, 92-98.

38. Lasbeur T (2017) Mortalité par accident de la vie courante en France métropolitaine, 2000-2012 (Mortality due to home and leisure injuries in mainland France, 2000-2012). Bull Epidem Hebdo 1, 34-40.

39. Szczesniak AS (2002) Texture is a sensory property. Food Qual Pref 13, 215-225.

40. Harris G (2008) Development of taste and food preferences in children. Curr Opin Clin Nutr Metab Care 11, 315-319.

41. Schwartz C, Vandenberghe-Descamps M, Sulmont-Rossé C, et al. (2017) Behavioral and physiological determinants of food choice and consumption at sensitive periods of the life span, a focus on infants and elderly. Innov Food Sci Emerg Technol 46, 91-106.

42. Schwartz C, Chabanet C, Lange C, et al. (2011) The role of taste in food acceptance at the beginning of complementary feeding. Physiol Behav 104, 646-652. 